Dr Vitomir Miladinović, profesor, dipl. inž.

\section{PALETNI LANCI U VOJNOM TRANSPORTU}

UDC: $355.69: 621.869 .8$

\begin{abstract}
Rezime:
Paletni sistem predstavlja osnovu snabdevanja u pozadinskom obezbedenju strategijsko-operativnih jedinica. Da bi se primena paletne tehnologije racionalno organizovala neop. hodno je formiranje logističkih transportnih lanaca od proizvodača do krajnjeg korisnika. $U$ ovom clanku prikazani su moguci paletni lanci $i$ njihove osnovne karike, čijim se kombinacijama formiraju. Kao kriterijumi za izbor optimalnog paletnog lanca u operativnom planiranju u miru uzeti su načini za utvrdivanje vrednosti po karikama lanca. Za izabrani paletni lanac izlożen je deterministicki model odredivanja broja paleta i potrebne mehanizacije za manipulaciju.
\end{abstract}

Ključne reči: paletni lanci, vojni transport, cena transportne usluge, bezbednost prevoza.

\title{
PALLET CHAINS IN MILITARY TRANSPORT
}

\section{Summary:}

The pallet system is essential in supply, especially in logistic support of strategic units. In order to organize rationally the application of the pallet technology, it is necessary to create logistic transport chains from the producer to the final user. Possible pallet chains are presented here as well as their basic forming links. The evaluation methods concerning shain links are taken as criteria for the choice of an optimal pallet chain in operational planning in peacetime. The deterministic model for working out a number of pallets and neccesary manipulation mechanization is presented for the chosen pallet chain.

Key words: pallet chains, military transport, transport service cost, transport safety.

\section{Uvod}

Iskustva iz perioda agresije NATO na našu zemlju, vezana za dotur $\mathrm{i}$ uspešnu disperziju materijalnih rezervi, potvrdila su opravdanost usvajanja i razvoja tehnologija integralnog transporta. Karakteristika ovog oblika transporta u Vojsci Jugoslavije jeste značajno razvijena materijalna baza i donekle infrastruktura, ali i potreba daljeg izučavanja i dogradnja organizacije uz primenu logističkih principa. U ovom clanku razmatrano je formi- ranje i izbor paletnih lanaca, određivanje potrebnog broja paleta i sredstava mehanizacije, kao osnove za racionalno organizovanje. Sa ovim pitanjima suočavaju se snabdevački organi pre svega tehničke i saobraćajne službe, pri primeni paletne tehnologije transporta.

\section{Oblici i karakteristike paletnih lanaca}

Savremene tehnologije transporta zavise od razvoja pomoćnih, manipulativ- 
nih i transportnih sredstava, koji omogucavaju ostvarivanje neprekinutih transportnih lanaca od proizvođača do krajnjih primalaca. Paletni transportni lanac definiše se kao integrisani i hronološki uređen skup procesa skladištenja, pretovara i transporta, kroz koji prolazi paleta kao tovarna jedinica, od obrazovanja kod pošiljaoca do rasformiranja kod primaoca. Tehnicku bazu sistema paletizacije čine palete, pretovarna mehanizacija $\mathrm{i}$ transportna sredstva.

Racionalizacija transportnih lanaca treba da omogući, u procesu eksploatacije kapaciteta automobilskih jedinica $\mathrm{i}$ skladišta, jednostavno i brzo biranje optimalnog paletnog lanca za zadate uslove. Najčešce je na raspolaganju mogućnost prevoza transportnim sredstvima drumskog i železničkog saobraćaja, kao i kombinacija drumskog i železničkog prevoza paletizovanih i nepaletizovanih tereta. Moguće je, ali znatno ređe, i korišćenje ostalih vrsta transporta.

Kao realno prihvatljive varijante mogu se formirati sledeći transportni lanci:

- direktan prevoz drumskim vozilima,

- direktan prevoz železnicom,

- kombinovan prevoz drumskim-železničkim vozilima.

Polazeći od tehnoloških procesa odvijanja paletnih lanaca, mogu se izdvojiti karakteristične faze od čijih su kombinacija sastavljeni [1]:

- utovar na drumska teretna vozila,

- utovar na železnickka kola,

- prevoz železnicom,

- prevoz drumskim motornim vozilima,

- pretovạr,

- istovar iz drumskih vozila,

- istovar iz železnickih kola.
Za organizovanje, utvrđivanje pojedinačnih troškova i izbor optimalnog lanca neophodno je da se sagledaju faze u transportnim lancima.

Oblici paletnih lanaca sa određenim tehnološkim rešenjima omogućavaju postizanje cilja, ali na različite načine i uz različite uslove. Koja ce varijanta biti izabrana zavisi od pravila po kojem ce se rešenje upoređivati $\mathrm{i}$ odabrati najbolje. Pravilo po kojem se obavlja upoređivanje (kriterijum), predstavlja meru dostizanja postavljenog cilja, a može se definisati i kao pravilo za utvrđivanje važnosti nekog cilja u hijerarhiji ukupnih ciljeva.

Po svom značenju kriterijum predstavlja osnovnu pretpostavku za mogućnost ocene kvaliteta razlicitih varijantnih tehnoloških rešenja. Pri izboru oblika paletnih lanaca u vojsci najčešći kriterijumi su: produktivnost, odnosno efikasnost; cena transportne usluge; vreme izvršenja zadatka; bezbednost pri radu.

Cena transportne usluge $\mathrm{i}$ bezbednost pri radu javljaju se kao osnovni kriterijumi za mirnodopske uslove kod operativnih planiranja, i biće razmatrane kao mera izbora u ovom članku.

\section{Struktura $\mathbf{i}$ cena transportne usluge kod paletnih lanaca}

Cena transportne usluge utvrđuje se preko transportnih troškova nastalih tokom izvršenja usluge. U odnosu na obim rada troškovi mogu biti, prema klasičnoj teoriji troškova, promenljivi i stalni [2, 3]. Promenljivi su oni troß̌kovi koji zavise od izvršenog transportnog rada i srazmerni su mu, što je veći rad i oni su veći. Za drumski transport to su troškovi za: potrošni materijal, tehničko održavanje vozila i zarade, ako se plaća prema radu. 
Stalni troškovi postoje bez obzira na to da li vozni park radi ili ne. Cine ih troskovi: amortizacije objekata, opreme i vozila, plata, ako je isplata prema vremenu, osiguranja, taksi, kamata, doprinosa $\mathrm{i}$ ostali troškovi režije.

Pri transportovanju železnicom javljaju se ovi isti troškovi, ali se prema VJ, kao korisniku usluge, javljaju kao ukupni, preko prevoznine.

Dopunski troškovi su troškovi utovara, istovara, održavanja tereta pri transportu i ostali troškovi transportnih operacija. Pri utvrđivanju cena u vojnom putnom transportu sopstvenim vozilima potrebno je uzeti u obzir, zbog komparativne analize, i dopunske troskove pored cisto transportnih, jer i oni ulaze u vrednost transportne usluge, odnosno koštaju VJ kao organizaciju.

Struktura cene transportne usluge $\mathrm{u}$ privredi prikazuje se preko troškova dohotka privredne organizacije. Formiranje struktura cena zavisi od karaktera privrednog sistema i od propisa preko kojih se taj sistem ispoljava. Ona je razlicita po granama transporta koje se javljaju kao karike paletnog lanca.

U cenu bilo kog proizvoda, cena transportne usluge ulazi u troškove prodaje. Transportni troškovi čne najveći deo prodajnih troškova, jer se u cene ugrađuju i ostali troškovi prometa vezani za administraciju, marketing, pakovanje, distribuciju, itd. Cene transporta u privredi više su od cena transporta vojnim motornim vozilima, zbog različite strukture troškova. Prema postojećoj regulativi u izračunavanju cene transporta vojnim vozilima ne uzima se $u$ obzir vrednost transportne usluge, već samo materijalni troškovi nastali zbog njenog obavljanja. Vrednost rada ljudi $i$ višak rada ne ulazi u cenu transportne usluge, pa je čine tri grupe troškova, i to: pogonski, amortizacioni i troškovi tehničkog održavanja.

Cene transportne usluge i struktura troškova razliciti su za pojedine subjekte koji su zainteresovani, odnosno uðestvuju u formiranju paletnih lanaca, kao što su transporteri (automobilske jedinice i železnica) i korisnici (pozadinske baze, jedinice $\mathrm{i}$ organi $\mathrm{VJ}$ ).

Svaki subjekt zainteresovan je za troškove koji su neposredno vezani za njega, što je kao procena (kao tačka) prikazano u tabeli 1 .

Pri izboru optimalnog lanca cena transportne usluge razmatra se sa aspekta automobilskih jedinica (ukupna cena korišćenja vozila), VJ (ukupna cena korišcenja vozila sa cenom mehanizovanog utovara-istovara) i železnice (cena prevoznine). Vrednost manuelnog rada vojnika, vozač i rukovaoca sredstvima mehanizacije, kao i troškovi pratioca pošiljki, može takođe biti uzeta u obzir pri izračunavanju cene transportne usluge.

Tabela 1

Veza subjekata i troß̌kova transporta

\begin{tabular}{|l|c|c|c|}
\hline \multirow{2}{*}{ Troskovi } & \multicolumn{3}{|c|}{ Subjekti } \\
\cline { 2 - 4 } & $\begin{array}{c}\text { Automobil- } \\
\text { ske jedinice }\end{array}$ & $\begin{array}{c}\text { Pozadin- } \\
\text { ske baze, } \\
\text { VJ }\end{array}$ & Zeleznica \\
\hline $\begin{array}{l}\text { a) Promenljivi: } \\
\text { - pogonski } \\
\text { - održavanje } \\
\text { - zarade }\end{array}$ & $\bullet$ & - & $\bullet$ \\
$\begin{array}{l}\text { b) Stalni: } \\
\text { - amortizacija }\end{array}$ & - & - & $\bullet$ \\
- plate & - & $\bullet$ & $\bullet$ \\
- osiguranja, \\
$\begin{array}{l}\text { takse, dopri- } \\
\text { nosi }\end{array}$
\end{tabular}




\section{Cena transportne usluge u}

drumskom $i$ železničkom transportu

Proračun cene transportne usluge po varijantama obavlja se na osnovu zbira parcijalnih troškova tehnoloških rešenja u okviru svakog transportnog lanca, odnosno svake varijante posebno. Cene transportne usluge, vezane za realizaciju pojedinih tehnologija u paletnom lancu izračunavaju se po osnovnim fazama cijim se zbirom dobijaju cene pojedinih lanaca.

\section{Cena utovara-istovara drumskih vozila}

Ova cena pojavljuje se kao parcijalni trošak kod varijanti u kojima se utovar-istovar obavlja mehanizovanim sredstvima, odnosno kod varijanti gde se kao tovarne jedinice koriste palete. Cena $\left(\mathrm{C}_{\text {uid }}\right)$ se dobija preko jedinačne cene po toni/čas $\left(C_{t}\right)$ iz cenovnika Pravila o korišcenju vozila VJ i vremena rada mehanizacije $\left(\mathrm{T}_{\mathrm{r}}\right)$ koje zavisi od proizvodnosti sredstava $\left(\mathrm{W}_{\mathrm{t}}\right)$ i kolicine koja se utovara-istovara na vozilo $\left(Q_{v}\right)$.

$$
\mathrm{C}_{\mathrm{uid}}=\mathrm{C}_{\mathrm{t}} \cdot \mathrm{T}_{\mathrm{r}}(\operatorname{din}), \mathrm{T}_{\mathrm{r}}=\frac{\mathrm{Q}_{\mathrm{v}}}{\mathrm{W}_{\mathrm{t}}}
$$

\section{Cena prevoza drumom}

Cena korišcenja vojnih teretnih vozila predstavlja trošak kod varijanti u kojima prevoz realizuju automobilske jedinice ili vozila VJ, direktno do korisnika ili do najbliže železničke stanice gde se obavlja pretovar.

Pravilo o korišćenju motornih vozila u VJ definiše da se upotreba vozila za realizaciju zadataka u transportu obavlja bez naplate troškova. Međutim, radi upoređenja sa ostalim oblicima prevoza, cena prevoza drumom $\left(\mathrm{C}_{\mathrm{kd}}\right)$ dobija se preko jedinačnih troškova $\left(\mathrm{C}_{1}\right)$, ukupno pređenog puta (L) i broja korišcenih vozila (A).

$$
\mathrm{C}_{\mathrm{kd}}=\mathrm{A} \cdot \mathrm{C}_{1} \cdot \mathrm{L}(\mathrm{din})
$$

\section{Cena prevoza železnicom}

Proračun cene prevoza železnicom obavlja se na osnovu Cenovnika železničkih usluga za unutrašnji saobraćaj, daljinara za prevoz stvari i putokaza. Na osnovu propisa o prevozu i računanju prevoznine reguliše se način proračuna cene prevoza koju VJ plaća Zajednici Jugoslovenskih železnica.

Pri prevozu železnicom paletni lanci se organizuju kao mešovita vojna prevoženja, koje čini prevoženje kola iz jedne otpremne za jednu uputnu stanicu, pod uslovom da to prevoženje planira vojna delegacija. U ovom prevoženju uð̌estvuju najmanje dvoja kola, od kojih jedna služe za prevoz pratnje.

Računska masa za mešovita vojna prevoženja (RM) utvrđuje se sabiranjem stvarne mase utovarenog tereta (materijalno-tehničkih sredstava) u svim teretnim kolima $\left(Q_{k}\right)$, i sopstvene mase kola od 25 tona za putnička kola.

$$
R M=\Sigma Q_{k}+25(t)
$$

Prosečna računska masa po jednim kolima $\left(\mathbf{R M}_{\mathrm{k}}\right)$ proračunava se tako da se ukupna računska masa utovarenog tereta podeli sa brojem upotrebljenih kola $\left(\mathrm{n}_{\mathrm{k}}\right)$ i zaokruži na $100 \mathrm{~kg}$ više.

$$
\mathrm{RM}_{\mathrm{k}}=\frac{\mathrm{RM}}{\mathrm{n}_{\mathrm{k}}}(\mathrm{t})
$$

Prevoznina $\left(\mathrm{C}_{\mathrm{kz}}\right)$, odnosno cena prevoza, računa se po I tarifskom razredu 
odgovarajućeg prevoznog stava iz tarife $\left(\mathrm{T}_{\mathrm{F}}\right)$, za utvrđenu prosečnu masu po jednim kolima $\left(\mathrm{RM}_{\mathrm{k}}\right)$, i tako izračunata prevoznina za jedna kola množi se sa ukupnim brojem korišcenih kola:

$$
\mathrm{C}_{\mathrm{kz}}=\mathrm{RM}_{\mathrm{k}} \cdot \mathbf{n}_{\mathrm{k}} \cdot \mathrm{T}_{\mathrm{FI}}(\mathrm{din})
$$

Ako se za mešovito vojno prevoženje zahteva poseban voz, prevoznina ne može biti manja od prevoznine izračunate za masu od $500000 \mathrm{~kg}$ po I tarifskom razredu, i 25-tonskom prevoznom stavu za određeno rastojanje.

\section{Cena utovara-istovara na železnici}

Cena ove karike lanca pojavljuje se kao parcijalni trošak kod varijanti u kojima se istovar obavlja mehanizovanim sredstvima, odnosno kod varijanti gde se kao tovarne jedinice koriste palete u skladištima sa vojnoindustrijskim kolosekom. Ova cena $\left(\mathrm{C}_{\text {uiz }}\right)$ dobija se po metodologiji izračnavanja cene utovara-istovara vozila $\left(\mathrm{C}_{\text {uid }}\right)$, sa vrednostima za sredstva koja se koriste.

\section{Cena pretovara}

Cena pretovara $\left(C_{p}\right)$ javlja se u slučaju nepostojanja vojnog industrijskog

Tabela 2

Matrica strukture cene transportne usluge paletnih lanaca

\begin{tabular}{|c|c|c|c|}
\hline \multirow[b]{2}{*}{ Struktura cena } & \multicolumn{3}{|c|}{ Paletni lanac } \\
\hline & $\begin{array}{l}\text { Drumski } \\
\text { transport }\end{array}$ & $\begin{array}{c}\text { Zeleznic- } \\
\text { ki tran- } \\
\text { sport }\end{array}$ & $\begin{array}{l}\text { Kombinova- } \\
\text { ni transport }\end{array}$ \\
\hline Utovar & $\mathrm{x}$ & $\mathbf{x}$ & $\mathbf{x}$ \\
\hline $\begin{array}{l}\text { Prevoz dru- } \\
\text { mom }\end{array}$ & $\mathrm{x}$ & & $\mathrm{x}$ \\
\hline Pretovar & & & $x$ \\
\hline $\begin{array}{l}\text { Prevoz } \\
\text { żeleznicom }\end{array}$ & & $\mathbf{x}$ & $\mathrm{x}$ \\
\hline Istovar & $x$ & $x$ & $x$ \\
\hline
\end{tabular}

koloseka u skladištima VJ, a za prevoz se koristi železnica. Ova cena obuhvata samo cenu utovara-istovara vozila, jer utovar-istovar železničkih kola ulazi u cenu prevoza železnicom.

Matrica strukture cena, odnosno troSkova koji su vezani za realizaciju svakog od mogucíh transportnih lanaca, kao osnove za cenu koja je kriterijum optimalnosti, prikazana je u tabeli 2 .

\section{Kriterijum bezbednosti prevoza i manipulacije}

Svako kretanje povezano je sa pojavom rizika za živote vojnika-vozača, rukovaoca mehanizacije i pratioca prevoza, te oštećenja (uništenja) tereta, odnosno tehničkih materijalnih sredstava. Potpuno eliminisanje rizika nije moguće. Priroda tereta, posebno opasnih materija, zahteva poklanjanje posebne pažnje pri prevoženju drumskim sredstvima ili železnicom, o čmu svedoci i niz propisa.

U VJ sistemski je rešeno da se prati samo bezbednost u drumskom saobracaju. Nezgode i oštećenja tereta u ostalim karikama paletnih lanaca registruju se i analiziraju samo kao vanredni događaji, prema regulativi za ovu oblast. Zbog parcijalnog praćenja nema odgovarajućih pokazatelja za stanje i karakteristike realizacije transporta primenom paletizacije.

Utvrđivanje konkretnih vrednosti kriterijuma zahtevalo bi opsežna istraživanja. $\mathrm{Za}$ optimizaciju izbora paletnih lanaca mogu se koristiti rezultati ankete utvrđene preko srednje vrednosti odgovora 10 eksperata sa ocenama u rasponu od 1 do 10 . Anketirani su načelnici saobraćajne službe, tehničke službe, komandiri automobilskih jedinica, starešine vojne delegacije i dr. Pošto je optimalan broj eksperata u granicama 6-22, ovi se 
- vreme obrta paleta, odnosno

Vrednosti kriterijuma bezbednosti

\begin{tabular}{|c|c|c|c|}
\hline \multirow{2}{*}{ Eksperti } & \multicolumn{3}{|c|}{ Ocene po paletnim lancima } \\
\cline { 2 - 4 } & $\begin{array}{c}\text { Drumski } \\
\text { transport }\end{array}$ & $\begin{array}{c}\text { Zeleznic- } \\
\text { ki tran- } \\
\text { sport }\end{array}$ & $\begin{array}{c}\text { Kombinova- } \\
\text { ni transport }\end{array}$ \\
\hline 1. & 7 & 9 & 5 \\
\hline 2. & 7 & 9 & 8 \\
\hline 3. & 5 & 3 & 8 \\
\hline 4. & 8 & 10 & 6 \\
\hline 5. & 7 & 10 & 6 \\
\hline 6. & 7 & 9 & 5 \\
\hline 7. & 8 & 10 & 6 \\
\hline 8. & 6 & 10 & 2 \\
\hline 9. & 7 & 10 & 5 \\
\hline 10. & 8 & 9 & 6 \\
\hline $\begin{array}{l}\text { Prosečna } \\
\text { vrednost }\end{array}$ & 7 & 8,9 & 5,7 \\
\hline
\end{tabular}

rezultati kao ocena trenutnog stanja bezbednosti transporta u paletnim lancima mogu prihvatiti [5]. Vrednosti ocena po varijantama date su u tabeli 3 [3].

Primenom programa višekriterijumskog rangiranja, preko kriterijuma cena transportne usluge i bezbednosti na radu, dobija se optimalan paletni lanac za konkretne uslove pojedinih transportnih zadataka.

\section{Određivanje broja paleta i sredstava manipulacije}

Da bi se kod operativnog planiranja izabrane varijante lanca mogao proračunati potreban broj paleta za formiranje paletnih jedinica dencanih tereta, neophodno je da budu poznati sledeći elementi:

- prosečna dnevna količina tereta iz otpravljanja i tranzita, između određenih sabirnih centara, koja se prema tehnološkom procesu može paletizovati;

- prosečna masa komadnih tereta, koja se može složiti na jednu paletu; vreme koje protekne od momenta završetka opterećenja paleta sa teretom, pa do njihovog ponovnog opterećenja [6].

Potreban broj paleta $\left(\mathrm{N}_{\mathrm{p}}\right)$ izračunava se po obrascu:

$$
\mathrm{N}_{\mathrm{p}}=\frac{\mathrm{Q}_{\mathrm{dp}}}{\mathrm{q}_{\mathrm{k}}} \cdot \mathrm{t}_{\mathrm{op}}
$$

gde je:

$\mathrm{Q}_{\mathrm{dp}}$ - dnevna količina tereta koji se može paletizovati (t),

$\mathrm{q}_{\mathrm{k}}$ - prosečna masa tereta koja se može smestiti na jednu paletu ( $\mathrm{t}$ ), $t_{\text {op }}$ - vreme obrta paleta (dana).

Svi denčani tereti koji se otpremaju ili tranzitiraju ne mogu se paletizovati. Prema iskustvu iz drugih zemalja, gde je razvijena primena paletizacije, pri dobroj organizaciji rada, paletizacijom može da se obuhvati oko $90 \%$ denčanih tereta koji se prevoze. Međutim, za naše uslove to iznosi $40-60 \%$. Ovaj odnos za vojna prevoženja određuju organi službi koje organizuju prevoz.

Dnevna količina tereta koji se može paletizovati izračunava se po obrascu:

$\mathrm{Q}_{\mathrm{dp}}=\mathrm{Q}_{\mathrm{d}} \cdot \alpha(\mathrm{t})$

gde je:

$\mathrm{Q}_{\mathrm{d}}$ - dnevna količina tereta koji se prevozi $(\mathrm{t})$, $\alpha$ - teret koji se paletizuje (\%).

Pri slaganju na palete, $s$ obzirom na vrstu i specifičnu masu tereta, vrstu $\mathrm{i}$ oblik ambalaže, kao i broj i masu komada, prosečna masa tereta koji se može smestiti na jednu paletu kreće se u granicama $0,25-0,6$ tona $[1,3]$.

Vreme obrta paleta, ako se pođe od pretpostavke da se paleta kreće skoro 
isto kao i denčani teret, jednako je ili manje od vremena roka za isporuku denCanog tereta $\left(\mathrm{t}_{\mathrm{d}}\right)$, odn.: $\mathrm{t}_{\mathrm{op}} \leq \mathrm{t}_{\mathrm{d}}$.

Zakonom o prevozu na Jugoslovenskim železnicama, određena je gornja granica roka isporuke, koja se sastoji od roka otpreme, prevoznog roka i roka izdavanja, a oni iznose:

- rok otpreme - 1 dan

- prevozni rok za:

- redovan prevoz i svakih otpočetih $250 \mathrm{~km}-1$ dan

- ubrzani prevoz i svakih otpočetih $350 \mathrm{~km}-1$ dan

- rok izdavanja - $12 \mathrm{~h}$

Kako je obrt palete $\left(t_{o p}\right)$ jednak ili manji od vremena obrta denčanog tereta, može se izračunati i obrt palete prema sledećem obrascu:

$$
t_{o p}=t_{o t}+t_{p r e v}+t_{i z d}(\text { dana })
$$

Vreme otpreme paleta $\left(\mathrm{t}_{\mathrm{ot}}\right)$ jeste vreme koje protekne od momenta njenog opterećenja pa do otpreme tereta sa paletom. Za svaki slučaj proračunava se za konkretne uslove ali, po pravilu, ne sme da bude duže od jednog dana.

Vreme prevoza palete $\left(t_{\text {prev }}\right)$ jeste vreme koje protekne od momenta njene otpreme do momenta pripreme za izdavanje. Ovo vreme zavisi od udaljenosti, pa za svakih $300 \mathrm{~km}$ puta obično iznosi 1 dan. Međutim, kada se raspolaže sa prosečnim putem prevoza tereta $\left(L_{\imath}\right)$ i komercijalnom brzinom $\left(\mathrm{V}_{\mathrm{k}}\right)$ onda ono iznosi:

$\mathrm{t}_{\mathrm{prev}}=\frac{\mathrm{L}_{\mathrm{t}}}{\mathrm{V}_{\mathrm{k}}}(\mathrm{h})$

Pošto se vreme prevoza palete izražava u danima, a u obrt ulazi i pređeni put do ponovnog utovara, konačan obrazac glasi:

$t_{\text {prev }}=\frac{2 L_{t}}{24 V_{k}}=\frac{L_{t}}{12 V_{k}}$ (dana)

Vreme izdavanja palete $\left(t_{i z d}\right)$ jeste vreme od prispeca palete sa teretom u stanicu do istovara palete u magacin ili skladište korisnika prevoza. Ovo vreme iznosi oko 12 casova, odn. 0,5 dana.

Prema tome, konačan obrazac za izračunavanje obrta paleta je:

$t_{o p}=t_{o t}+\frac{L_{t}}{12 \cdot V_{k}}+t_{i z d}($ dana $)$

Potreban broj angažovane mehanizacije (viljuškara ili DHP dizalica), zavisi od dnevne količine tereta koju treba utovariti, istovariti ili preneti sa jednog na drugo manipulaciono mesto.

$\mathrm{Za}$ manje količine i lakše paletne jedinice obično se koriste ručni viljuškari. Međutim, kada je rastojanje od mesta utovara (ili istovara) do mesta slaganja, i obrnuto, veće od $50 \mathrm{~m}$, ili kada su pojedine paletne jedinice teže od $500 \mathrm{~kg}$, ili kada se utovar ili istovar vozila obavlja u nivou, bez rampe, koriste se viljuškari ili DHP dizalice.

Imajući u vidu da odgovarajuća mehanizacija spada u mašine ciklusnog dejstva, potreban broj mehanizacije $\left(\mathrm{N}_{\mathrm{m}}\right)$ izračunava se po obrascu:

$\mathrm{N}_{\mathrm{m}}=\frac{\mathrm{Q}}{\mathrm{n}_{\mathrm{c}} \cdot \mathrm{T}_{\mathrm{s}} \cdot \mathrm{q}_{\mathrm{k}}}$

gde je:

Q, - ukupna dnevna količina tereta kojom se manipuliše $(t)$;

$\mathrm{n}_{\mathrm{c}}$ - broj ciklusa u jednom casu. Izračunava se izrazom $n_{c}=3600 / T_{c}$, gde je 
$T_{c}$ (sec) vreme trajanja jednog ciklusa između dva zahvata paletne jedinice; $\mathrm{T}_{\mathrm{s}}$ - trajanje manipulacije kod većih skladišnih kompleksa u jednoj smeni (obično $8 \mathrm{~h}$ ), odnosno rada na pretovaru.

Kako radnim parkom treba obuhvatiti i mehanizaciju koja je na tekućem i investicionom održavanju, broj sredstava parka treba uvećati koeficijentom koji se u standardnim uslovima rada kreće od 1,10 do 1,15 , odn. i do 1,5 .

Pored deterministickog prilaza moguce je određivanje potrebnog broja paleta i mehanizacije i preko stohastičkih modela $\mathrm{i}$ troškovnom funkcijom cilja.

\section{Zaključak}

Karakteristika dostignutog nivoa razvoja paletizacije u pozadinskom obezbeđenju VJ jeste razvijena materijalna baza i u manjoj meri infrastruktura, kao i potreba dogradnje organizacije uz primenu logistickih principa.

Racionalna organizacija paletne tehnologije zasniva se na formiranju paletnih lanaca, ciji oblici zavise od transportnih grana, skladištenja i zahteva za manipulaciju teretima. Polazeći od toga, što predstavlja osnovnu kariku cijim se raznim kombinacijama dobijaju paletni lanci, izdvojeni su utovari $\mathrm{i}$ istovari kod odgovarajucih transportnih grana, prevozi i pre- tovari. Kao kriterijum za izbor optimalnog lanca za operativna planiranja u miru uzeti su cena transportne usluge $i$ bezbednost rada.

$\mathrm{Za}$ utvrđivanje cene transportne usluge razmatrana je njihova struktura u saobraćajno-transportnim organizacijama i VJ, kao i primena za svaku kariku paletnog lanca. Kod kriterijuma bezbednosti nepovoljno je što se u VJ sistemski prati samo stanje u vojnom putnom saobraćaju, pa su predložene veličine dobijene istraživanjima na osnovu procene starešina koje neposredno organizuju ili realizuju prevoz primenom paletne tehnologije.

$\mathrm{Za}$ određivanje potrebnog broja paleta i mehanizacije na osnovu iskustava stečenih u saobraćajno-transportnim organizacijama i VJ, predloženi su odgovarajući deterministicki modeli, jer za primenu drugih, pre svega stohastičkih modela, još uvek nema uslova.

\section{Literanura:}

[1] Miladinovic, V.: Integralni transport, predavanja, Vojnotebnicka akademija, Beograd, 1999.

[2] Miladinovic, V: Organizacija putnog transporta, skripta, Tehni¿ki 3kolski centar, Zagreb, 1976.

[3] Bojanic, I.: Izbor optimalnog transportnog lanca kod slanja municije na remont, diplomski rad, VojnotehniCka akademija, Beograd, 1997.

[4] Pravilo o koriscenju motornih vozila VJ u miru i ratu, Saobracajna uprava GS, Beograd, 1995.

[5] Somođi, \$.: Metodi ekspertskih misljenja u pripremanju i donołenju odluka, Direktor br. 3, Beograd, 1987.

[6] Cokic, R.: Jedan od metoda proračuna potrebe sredstava paletizacije, Manipulacija skladistenje br. 2, Beograd, 1974. 